\title{
EFEITO DA APLICAÇÃO DO CLORETO DE CÁLCIO NOS FRUTOS DA MANGA 'TOMMY ATKINS' TRATADOS HIDROTERMICAMENTE1
}

\author{
MURILLO FREIRE JÚNIOR² e ADIMILSON BOSCO CHITARRA 3
}

\begin{abstract}
RESUMO - O objetivo do trabalho foi estudar os efeitos da aplicação de cloreto de cálcio, associado ao tratamento hidrotérmico em frutos de manga (Mangifera indica L.). Verificou-se que a associação do tratamento hidrotérmico à aplicação de cloreto de cálcio é viável, e que existe uma correlação positiva entre o $\mathrm{Ca}$ aplicado e a quantidade deste elemento na casca, porém com pouca penetração para a polpa do fruto, o que demonstra que o $\mathrm{Ca}$ age positivamente na diminuição dos sintomas da antracnose. Pelo contraste apresentado na aparência externa dos frutos, a aplicação de cloreto de cálcio a $4 \%$ mostrou melhores resultados, porém sem garantir a qualidade final exigida para a exportação dos frutos. A aplicação de cloreto de cálcio não se mostrou efetiva no aumento do período de conservação dos frutos.
\end{abstract}

Termos para indexação: Mangifera indica, tratamento pós-colheita.

\section{EFFECT OF CALCIUM CHLORIDE APPLICATION \\ ON MANGO FRUIT CV. TOMMY ATKINS HYDROTHERMALLY TREATED}

\begin{abstract}
The aim of this work was to study the effects of the application of calcium chloride associated with hydrothermal treatment on post-harvest preservation of mango fruit (Mangifera indica $\mathrm{L}$.). The $\mathrm{Ca}$ absorption by mango peel and flesh was investigated using the same conditions usually employed for the fruit exportation to the american market. It was verified that the association of heat treatment to $\mathrm{Ca}$ application was viable. There was a positive correlation between the amount of $\mathrm{Ca}$ applied and the amount of this element presented in the peel, although low penetration toward the flesh was observed. It was demonstrated that Ca reduces anthracnose symptoms. It was also verified, by observing the external appearance of the fruits, that the best results were obtained when $4 \%$ of calcium chloride was used, although such concentration did not guarantee the required quality for the fruit exportation. The calcium chloride application was not effective to increase the shelf-life of the fruits.

Index terms: Mangifera indica, post harvest treatment.
\end{abstract}

\section{INTRODUÇÃO}

Os estados do Nordeste do Brasil têm estimulado o plantio da mangueira visando ao mercado externo e interno. A produção dos pomares em regiões semi-áridas, como nos pólos Petrolina/Juazeiro e Mossoró/Açu, oferece frutos precoces ou tardios,

\footnotetext{
${ }^{1}$ Aceito para publicação em 15 de setembro de 1998.

${ }^{2}$ Eng. Agr., M.Sc., Embrapa-Centro Nacional de Pesquisa de Tecnologia Agroindustrial de Alimentos (CTAA), Av. das Américas, 29501, Guaratiba, CEP 23020-470 Rio de Janeiro, RJ. E-mail: mfreire@ctaa.embrapa.br

${ }^{3}$ Eng. Agr., Ph.D., Universidade Federal de Lavras (UFLA), Caixa Postal 37, CEP 37200-000 Lavras, MG.
}

suprindo a demanda desta fruta no exterior nos meses em que a oferta é inexistente, e ainda supera, qualitativamente, as produções do Estado de São Paulo, notadamente na redução da incidência de doenças (Instituto Brasileiro de Frutas, 1993).

Os mercados para as exportações são muitos exigentes quanto à qualidade dos frutos, porém os frutos tropicais não resistem mais do que 20 dias ao transporte marítimo com as tecnologias atuais de pré e pós-colheita. É necessário prolongar de uma para duas semanas a vida pós-colheita dos frutos, para viabilizar o transporte marítimo, cujo custo do frete é inferior ao transporte aéreo (Filgueiras, 1990).

Segundo o Instituto Brasileiro de Frutas (1993), as exportações de manga em 1992 foram destinadas 
principalmente aos Estados Unidos (74\%), o que revela a importância do mercado americano, que tem características e exigências específicas, como o tratamento hidrotérmico pós-colheita, destinado ao controle dos ovos e larvas das moscas das frutas, tais como Anastrepha obliqua, Anastrepha fraterculus e Ceratitis capitata (Cunha et al.,1993).

Muitos frutos da mangueira, como os da cultivar Tommy Atkins, que é a mais comercializada, podem apresentar um grave defeito interno, denominado colapso interno, que dificilmente é detectado externamente no momento da sua colheita. Conforme a intensidade da lesão, uma parte importante da polpa se transforma numa gelatina marrom, o que torna o fruto impróprio para o consumo. É desconhecido, até o momento, o agente biótico causal; a lesão é classificada como distúrbio fisiológico. Esse problema constitui um obstáculo para a expansão do mercado da manga nos países da Europa e nos Estados Unidos (Gorgatti Netto et al.,1993).

O Ca tem um papel importante na redução e no controle do desenvolvimento de muitas desordens fisiológicas em frutos (Poovaiah,1988; Conway et al., 1994), podendo minimizar o problema quando aplicado na pré ou pós-colheita.

Segundo Marschener (1986), o Ca é essencial para a manutenção da estabilidade da membrana plasmática, e na sua deficiência, o fluxo de compostos de baixo peso molecular (açúcares) do citoplasma para o apoplasto aumenta, facilitando o desenvolvimento de fungos parasitas, que terão maior abundância de substratos.

O Ca torna os materiais da parede celular menos acessíveis à ação das enzimas hidrolizantes, e também reduz a degradação das paredes celulares por enzimas microbianas ou de origem fúngica (Poovaiah, 1988).

Diversos fatores, como a região de origem, a cultivar e o estádio de maturação podem afetar a absorção do Ca e a resposta do fruto ao nutriente (Chettri et al., 1991). Estudos comprovam que a aplicação de $\mathrm{Ca}$ aumenta a vida útil pós-colheita de dois para seis dias, dependendo da cultivar (Aina \& Oladunjoye, 1993). No entanto, a alternativa de se aplicar Ca antes da colheita é discutível, dada a baixa mobilidade do elemento no floema e sua baixa translocação a partir do local de aplicação (Chamel, 1989).
Vários autores citados por Yuen et al. (1993) demonstraram que o amadurecimento de mangas pode ser retardado por infiltração de $\mathrm{Ca}$ a vácuo. $\mathrm{O}$ dano na casca do fruto, resultante da aplicação de Ca por este modo, foi o maior problema encontrado, a limitar o seu uso como tratamento pós-colheita comercialmente viável.

Observando-se também pelo lado operacional, esta forma de aplicação de Ca é simples e viável, não causa transtornos e nem grandes investimentos nas instalações das empresas que já exportam manga para o mercado americano.

O objetivo deste trabalho foi estudar os efeitos da aplicação do cloreto de cálcio na pós-colheita, associado ao tratamento hidrotérmico de frutos de manga.

\section{MATERIAL E MÉTODOS}

As amostras dos frutos da mangueira cv. Tommy Atkins foram colhidas no mês de maio/97, provenientes de pomar comercial da empresa FRUNORTE, localizada em Mossoró, RN, onde as práticas culturais pré-colheita foram as recomendadas para os pomares comerciais da região. Os frutos foram colhidos no estádio de maturação pré-climatérico. Os tratamentos pós-colheita foram realizados em conformidade com as Normas para Exportação de Frutos para os Estados Unidos (Gorgatti Netto et al.,1993), da seguinte forma: imersão dos frutos a uma profundidade mínima de $12 \mathrm{~cm}$ em relação à superfície da água em soluções de cloreto de cálcio nas concentrações de $0 \%$ (controle), $2 \%$ e $4 \%$ respectivamente, à temperatura de $46,1^{\circ} \mathrm{C}$, durante 90 minutos. Após o tratamento hidrotérmico, os frutos foram resfriados à temperatura ambiente, com auxílio de ventilador, durante 30 minutos, embalados adequadamente, em caixas de papelão tipo exportação, e armazenados em câmara frigorífica a uma temperatura de $10^{\circ} \mathrm{C} \pm 1{ }^{\circ} \mathrm{C}$, com umidade relativa do ar entre $80 \%$ e $90 \%$, por 22 dias.

A aparência externa foi avaliada por método subjetivo, atribuindo-se notas de 1 a 5 , mediante a porcentagem da área superficial afetada com manchas nos frutos de cada tratamento, de acordo com Miccolis \& Saltveit (1995): $1,0=$ ausência de manchas ou lesões; $2,0=0 \%$ a $10 \%$ com manchas ou lesões (leve); $3,0=10 \%$ a $30 \%$ com manchas ou lesões (moderada); 4,0 = 30\% a 50\% com manchas ou lesões (severa); 5,0 = mais de 50\% com manchas ou lesões (extrema).

A aparência interna dos frutos com colapso foi avaliada por escala subjetiva, em que os frutos receberam notas 
de 1 a 5 mediante a medição da área do mesocarpo afetada: $1,0=$ ausência de colapso interno; $2,0=0 \%$ a $10 \%$ da área afetada (leve); $3,0=10 \%$ a 30\% da área afetada (moderada); $4,0=30 \%$ a $50 \%$ da área afetada (severa); $5,0=$ mais de $50 \%$ da área afetada (extrema).

A análise microbiológica, feita após a incubação dos frutos com sintomas de doenças, foi realizada com o isolamento e a identificação do patógeno, por meio de microscopia. O Ca total foi avaliado na casca e na polpa dos frutos, após digestão nitroperclórica e quantificação por espectrofotometria de absorção atômica, segundo metodologia de Sarruge \& Haag (1974), e os resultados, expressos em porcentagem

A textura foi determinada retirando-se três pequenas porções da casca por fruto, e medindo-se a textura com auxílio de um penetrômetro, Magness-Taylor modelo 30 A com ponta simetricamente cônica (diâmetro: $0,77 \mathrm{~cm}$ e comprimento, $3,10 \mathrm{~cm}$ ), conforme McCollum et al. (1989)

Realizou-se a média aritmética em cada parcela, expressando-se os resultados em newtons

A pectina total foi extraída da polpa utilizando-se a metodologia adaptada de McCready \& McComb (1952) e dosadas segundo Blumenkrantz \& Asboe-Hansen (1973), após reação com metahidroxifenil. Os resultados foram expressos em mg de ácido galacturônico por $100 \mathrm{~g}$ de polpa.

Após o descascamento manual dos frutos e a retirada do endocarpo, a polpa foi homogeneizada com auxílio de liquidificador e submetida às seguintes análises: $\mathrm{o} \mathrm{pH}$ foi determinado com o uso de potenciômetro digital, conforme as normas do Instituto Adolfo Lutz (1976); a acidez total titulável (ATT) foi avaliada através de titulação com $\mathrm{NaOH} 0,1 \mathrm{~N}$ e indicador fenolftaleína, também segundo as normas do Instituto Adolfo Lutz (1976), expressandose os resultados em porcentagem de ácido cítrico; os sólidos solúveis totais (SST) foram determinados com uso de refratrômetro digital, conforme as normas da Association of Official Agricultural Chemists (1990), expressando-se os resultados em ${ }^{\circ}$ Brix; e a relação SST/ATT foi obtida pela divisão dos SST pela ATT.

As análises foram realizadas aos $0,8,15$ e 22 dias de armazenamento refrigerado e, em seguida, os frutos foram colocados à temperatura ambiente, para completo amadurecimento.

O delineamento experimental adotado foi o inteiramente casualizado, com três repetições, sendo cada unidade experimental representada por três frutos. Foi realizada análise estatística, para verificar a existência de correlação entre o Ca na casca e na polpa, mediante o programa estatístico STATGRAPHIC, assim como análise de variância e comparação múltipla de médias entre o $\mathrm{Ca}$ adicionado na casca e polpa e o tempo de armazenamento. Também, foi realizada análise de variância e comparação múltipla de médias pelo teste de Tukey, a 5\% de probabilidade, entre a porcentagem de Ca utilizada nos tratamentos, os tempos de armazenamento, e as características dos frutos.

\section{RESULTADOS E DISCUSSÃO}

Apresentam-se, na Tabela 1, os valores médios das notas atribuídas à aparência dos frutos ao longo do armazenamento, submetidos aos diferentes tratamentos.

Os frutos, em todos os tratamentos, revelaram boa aparência externa, sem manchas ou podridões, firmes ao tato e com coloração normal, até o oitavo

TABELA 1. Médias das notas atribuídas à aparência da manga cv. Tommy Atkins submetida à imersão pós-colheita a $46,1^{\circ} \mathrm{C}$, por 90 minutos em $\mathrm{CaCl}_{2}$ e armazenada sob refrigeração por 22 dias $\left(10^{\circ} \mathrm{C} \pm 1^{\circ} \mathrm{C}\right.$ e $85 \% \pm 5 \%$ de umidade relativa) 1 .

\begin{tabular}{cccc}
\hline \multirow{2}{*}{$\begin{array}{c}\text { Armazenamento } \\
\text { (dias) }\end{array}$} & \multicolumn{3}{c}{ Tratamentos $\left(\mathrm{CaCl}_{2}\right)$} \\
\cline { 2 - 4 } & $0 \%$ & $2,0 \%$ & $4,0 \%$ \\
\hline & \multicolumn{3}{c}{ Aparência externa ${ }^{2}$} \\
8 & $1,0 \mathrm{a}$ & $1,0 \mathrm{a}$ & $1,0 \mathrm{a}$ \\
15 & $1,0 \mathrm{a}$ & $1,0 \mathrm{a}$ & $1,0 \mathrm{a}$ \\
22 & $2,7 \mathrm{a}$ & $2,0 \mathrm{a}$ & $1,6 \mathrm{a}$ \\
& $2,9 \mathrm{a}$ & $2,3 \mathrm{a}$ & $2,1 \mathrm{a}$ \\
\hline & \multicolumn{3}{c}{ Aparência interna ${ }^{3}$} \\
8 & $1,0 \mathrm{a}$ & $1,0 \mathrm{a}$ & $1,0 \mathrm{a}$ \\
15 & $1,0 \mathrm{a}$ & $1,2 \mathrm{a}$ & $1,4 \mathrm{a}$ \\
22 & $1,0 \mathrm{a}$ & $1,0 \mathrm{a}$ & $1,3 \mathrm{a}$ \\
\hline
\end{tabular}

1 Valores seguidos pelas mesmas letras na horizontal não diferem entre si pelo teste de Tukey, a $5 \%$ de probabilidade.

2 Escala subjetiva: 1, $0=$ ausência de manchas ou lesões; $2,0=0 \%$ a $10 \%$ com manchas ou lesões; $3,0=10 \%$ a $30 \%$ com manchas ou lesões; $4,0=30 \%$ a $50 \%$ com manchas ou lesões; $5,0=$ mais de $50 \%$ com manchas ou lesões

${ }^{3}$ Escala subjetiva: 1,0 = ausência de colapso interno; 2,0 = 0\% a 10\% da área afetada; $3,0=10 \%$ a $30 \%$ da área afetada; $4,0=30 \%$ a $50 \%$ da área afetada; $5,0=$ mais de $50 \%$ da área afetada (extrema) 
dia de armazenamento. No entanto, a partir do 15o dia, houve, no tratamento-controle, a incidência de manchas leves a moderadas, bem como nos frutos tratados com $\mathrm{CaCl}_{2}$ a $2 \%$, ao passo que os tratados com $\mathrm{CaCl}_{2}$ a $4 \%$ só manifestaram incidência leve de manchas a partir do 22 dia do armazenamento. Os frutos apresentaram manchas irregulares, mais escuras que as do tecido normal, e houve caso de desenvolvimento de pequenas pintas pretas. A incidência dos sintomas aumentou até o final do período do armazenamento, e foi mais acentuada nos frutos do tratamento-controle.

Pela análise microbiológica, foi constatado tratar-se de sintomas de antracnose, provocada por Colletotrichum gloeosporioides. A incidência de fungos patogênicos foi observada em todos os tratamentos, mas os sintomas diminuíram sensivelmente diante de maior quantidade de Ca presente na casca, o que confirma as observações de Poovaiah (1988), de que o Ca fortalece as paredes celulares, tornando-as menos acessíveis à ação de patógenos. Conforme se observa pela análise de regressão, não houve diferença entre médias nas diferentes concentrações quando comparadas duas a duas, mas houve diferença significativa entre a média do controle $(0 \%)$ e a média das duas outras concentrações $(2 \%$ e 4\%). Assim, a adição do Ca provocou alteração na aparência externa.

Apresenta-se, também, na Tabela 1, o comportamento da aparência interna dos frutos, submetidos aos diferentes tratamentos, ao longo do armazenamento. Observa-se, inicialmente, que os frutos, em todos os tratamentos, estavam sadios e sem colapso interno. No $8^{\circ} \mathrm{dia}$, a cada nove frutos, um apresentou colapso interno nos tratamentos quando se utilizou $2 \%$ e $4 \%$ de $\mathrm{CaCl}_{2}$. No $15^{\circ}$ dia, um em nove frutos apresentou a mesma desordem no tratamento com $4 \%$ de $\mathrm{CaCl}_{2}$. Do $22^{\circ}$ dia, quando foram retirados da câmara de refrigeração, até o final do período de observação (quarto dia ao ambiente), todos os frutos, independentemente do tipo de tratamento, não apresentaram colapso interno. Isso indica que a desordem observada, respectivamente, no $8^{\circ}$ e no $15^{\circ}$ dia, não foi causada pelo tratamento aplicado, $\mathrm{e}$ sim, provavelmente, por fenômeno ao acaso e isolado. Considerando-se esses resultados, o colapso interno da polpa ocorreu em pequena escala, de forma aleatória, nos frutos amostrados, e foi independente do tratamento aplicado. Examinando-se os dados através da análise de regressão e comparação múltipla das médias das notas atribuídas para a aparência interna, não houve diferenças significativas quanto aos níveis de Ca adicionado, nem quanto ao tempo de armazenamento.

Em todos os tratamentos, o comportamento do Ca foi semelhante durante o período de armazenamento, com aumento tanto na casca quanto na polpa, sendo os teores proporcionalmente maiores nos frutos submetidos à aplicação de $2 \%$ e $4 \%$ de $\mathrm{CaCl}_{2}$, em relação aos do tratamento-controle (Tabela 2). A correlação entre o Ca na casca e na polpa está apresentada na Fig. 1, que contém o gráfico ilustrando a correlação positiva entre a quantidade de Ca na casca e na polpa dos frutos, e pode ser observada uma tendência linear, o que indica que a quantidade de Ca na casca e na polpa dos frutos aumentou com o aumento da quantidade de Ca utilizada no tratamento. O coeficiente de correlação estimado foi de 0,7613 , com $\alpha \leq 0,05$. Considerando-

TABELA 2. Valores médios de Ca total na casca e na polpa da manga cv. Tommy Atkins submetida a imersão pós-colheita a $46,1^{\circ} \mathrm{C}$ por 90 minutos em $\mathrm{CaCl}_{2}$ e armazenada sob refrigeração por 22 dias $\left(10^{\circ} \mathrm{C} \pm 1^{\circ} \mathrm{C}\right.$ e $85 \% \pm 5 \%$ de umidade relativa) $)^{1}$.

\begin{tabular}{cccc}
\hline \multirow{2}{*}{$\begin{array}{c}\text { Armazenamento } \\
\text { (dias) }\end{array}$} & \multicolumn{3}{c}{ Tratamentos $\left(\mathrm{CaCl}_{2}\right)$} \\
\cline { 2 - 4 } & $0 \%$ & $2,0 \%$ & $4,0 \%$ \\
\hline \multicolumn{3}{c}{ Cálcio na casca } \\
0 & $0,280 \mathrm{a}$ & $0,318 \mathrm{~b}$ & $0,434 \mathrm{c}$ \\
8 & $0,243 \mathrm{a}$ & $0,369 \mathrm{~b}$ & $0,424 \mathrm{c}$ \\
15 & $0,292 \mathrm{a}$ & $0,365 \mathrm{~b}$ & $0,461 \mathrm{c}$ \\
22 & $0,372 \mathrm{a}$ & $0,417 \mathrm{~b}$ & $0,484 \mathrm{c}$ \\
\hline \multicolumn{3}{c}{ Cálcio na polpa } \\
0 & $0,054 \mathrm{a}$ & $0,062 \mathrm{~b}$ & $0,074 \mathrm{c}$ \\
8 & $0,067 \mathrm{a}$ & $0,089 \mathrm{~b}$ & $0,123 \mathrm{c}$ \\
15 & $0,090 \mathrm{a}$ & $0,109 \mathrm{~b}$ & $0,134 \mathrm{c}$ \\
22 & $0,103 \mathrm{a}$ & $0,124 \mathrm{~b}$ & $0,146 \mathrm{c}$ \\
\hline
\end{tabular}

1 Valores seguidos pelas mesmas letras na horizontal não diferem entre si pelo teste de Tukey, a $5 \%$ de probabilidade. 
se a análise de comparações múltiplas de médias do teor de Ca na casca e na polpa, houve diferenças significativas nas diferentes concentrações de $\mathrm{Ca}$ adicionado (Tabela 2). Resultados semelhantes foram obtidos mediante o teste estatístico nãoparamétrico de Friedman (Tabela 3).

Apresenta-se, na Tabela 4, o comportamento da textura dos frutos, submetidos aos diferentes tratamentos, ao longo do armazenamento. Os frutos apresentaram inicialmente valores correspondentes a cerca de 124,55 newtons, em todos os tratamentos, e no final do armazenamento a $10^{\circ} \mathrm{C}$ (22 dias) apresentaram uma resistência de 103,69, 120,90 e 109,87 newtons, respectivamente, nos tratamentos de $0 \%$; $2 \%$ e $4 \%$ de $\mathrm{CaCl}_{2}$. Observa-se que no $22^{\circ}$ dia de armazenamento não houve diferença acentuada na resistência dos frutos, independentemente do tratamento utilizado. As diferenças observadas no decorrer do armazenamento só podem ser explicadas por problemas de amostragem. Pela análise de regressão e a comparação múltipla das médias observadas não houve diferenças significativas quanto aos níveis de $\mathrm{Ca}$ adicionado.

Apresenta-se, também, na Tabela 4, o comportamento da quantidade de pectina total dos frutos sub-

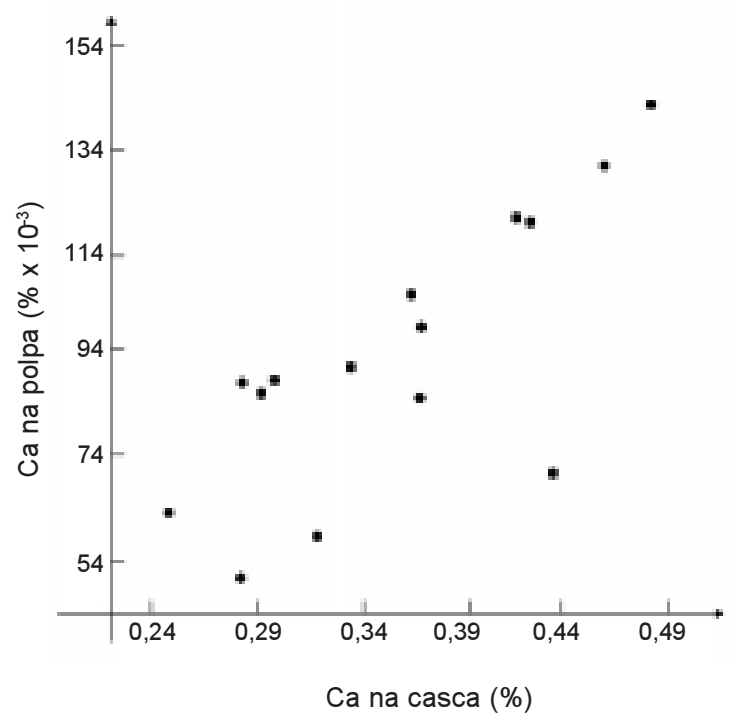

FIG. 1. Correlação entre o Ca na casca e Ca na polpa $\left(r^{2}=76,13 \%\right)$. metidos aos diferentes tratamentos, ao longo do armazenamento. Pelos resultados, a quantidade de pectina total não foi alterada durante todo o período de armazenamento. Pela análise de regressão e comparação múltipla das médias observadas, não houve diferenças significativas quanto aos níveis de $\mathrm{Ca}$ adicionado, nem quanto ao tempo de armazenamento.

TABELA 3. Teste de Friedman sobre Ca adicionado na casca e polpa da manga cv. Tommy Atkins ${ }^{1}$.

\begin{tabular}{ccc}
\hline Nível & Tamanho da amostra & Grau médio \\
\hline 0 & 5 & 1,20000 \\
2 & 5 & 1,80000 \\
4 & 5 & 3,00000 \\
\hline
\end{tabular}

1 Teste estatístico $=8,4$; nível de significância $=0,0149956$.

TABELA 4. Valores médios para textura e pectina total da manga cv. Tommy Atkins submetida a imersão pós-colheita a $46,1^{\circ} \mathrm{C}$, por 90 minutos, em $\mathrm{CaCl}_{2}$, e armazenada sob refrigeração, por 22 dias $\left(10^{\circ} \mathrm{C} \pm 1^{\circ} \mathrm{C}\right.$ e $85 \% \pm 5 \%$ de umidade relativa) ${ }^{1}$.

\begin{tabular}{|c|c|c|c|}
\hline \multirow{2}{*}{$\begin{array}{l}\text { Armazenamento } \\
\text { (dias) }\end{array}$} & \multicolumn{3}{|c|}{ Tratamentos $\left(\mathrm{CaCl}_{2}\right)$} \\
\hline & $0 \%$ & $2,0 \%$ & $4,0 \%$ \\
\hline & \multicolumn{3}{|c|}{ Textura (Newtons) } \\
\hline 0 & $125,04 \mathrm{a}$ & $126,91 \mathrm{a}$ & $125,44 a$ \\
\hline 8 & $121,17 \mathrm{a}$ & $98,53 \mathrm{a}$ & $85,98 \mathrm{a}$ \\
\hline 15 & $119,08 \mathrm{a}$ & $104,76 a$ & $90,88 \mathrm{a}$ \\
\hline \multirow[t]{2}{*}{22} & $103,69 a$ & $120,90 \mathrm{a}$ & $109,87 \mathrm{a}$ \\
\hline & \multicolumn{3}{|c|}{$\begin{array}{l}\text { Pectina total } \\
\text { (mg ác. galacturônico/100 g) }\end{array}$} \\
\hline 0 & $793,12 \mathrm{a}$ & $765,53 a$ & $754,15 a$ \\
\hline 8 & $782,77 \mathrm{a}$ & $793,75 a$ & $839,22 \mathrm{a}$ \\
\hline 15 & $803,46 a$ & $800,02 \mathrm{a}$ & $813,46 a$ \\
\hline 22 & $806,91 \mathrm{a}$ & $768,98 \mathrm{a}$ & $779,33 \mathrm{a}$ \\
\hline
\end{tabular}

1 Valores seguidos pelas mesmas letras na horizontal não diferem entre $\mathrm{s}$ pelo teste de Tukey, a 5\% de probabilidade.

Pesq. agropec. bras., Brasília, v.34, n.5, p.761-769, maio 1999 
Apresenta-se, na Tabela 5, o comportamento do pH, de acidez e dos sólidos solúveis, e a relação sólidos solúveis/acidez dos frutos submetidos aos diferentes tratamentos, ao longo do armazenamento. Observa-se que os frutos submetidos aos três tratamentos apresentam comportamento semelhante durante o armazenamento. Quanto à acidez, observase, inicialmente, um ligeiro decréscimo e valores entre 0,91 e 0,95 . Pela análise de regressão e comparação múltipla das médias observadas, houve di-

TABELA 5. Valores médios das características intrínsecas da manga cv. Tommy Atkins submetida a imersão pós-colheita a $46,1^{\circ} \mathrm{C}$, por 90 minutos, em $\mathrm{CaCl}_{2}$, armazenada por 22 dias $\left(10^{\circ} \mathrm{C} \pm 1^{\circ} \mathrm{C}\right.$ e $85 \% \pm 5 \%$ de umidade relativa) ${ }^{1}$.

\begin{tabular}{|c|c|c|c|}
\hline \multirow{2}{*}{$\begin{array}{l}\text { Armazenamento } \\
\text { (dias) } \\
\end{array}$} & \multicolumn{3}{|c|}{ Tratamentos $\left(\mathrm{CaCl}_{2}\right)$} \\
\hline & $0 \%$ & $2,0 \%$ & $4,0 \%$ \\
\hline & \multicolumn{3}{|c|}{$\mathrm{pH}$} \\
\hline 0 & $3,52 \mathrm{a}$ & $3,57 \mathrm{a}$ & $3,50 \mathrm{a}$ \\
\hline 8 & $3,47 \mathrm{a}$ & $3,40 \mathrm{a}$ & $3,41 \mathrm{a}$ \\
\hline 15 & $3,41 \mathrm{a}$ & $3,47 \mathrm{a}$ & $3,44 a$ \\
\hline \multirow[t]{2}{*}{22} & $3,72 \mathrm{a}$ & $3,67 \mathrm{a}$ & $3,83 \mathrm{a}$ \\
\hline & \multicolumn{3}{|c|}{$\begin{array}{l}\text { Acidez total titulável } \\
\text { (\% de ácido cítrico) }\end{array}$} \\
\hline 0 & $0,91 \mathrm{a}$ & $0,95 \mathrm{ab}$ & $0,95 \mathrm{ab}$ \\
\hline 8 & $0,78 \mathrm{a}$ & $0,83 \mathrm{ab}$ & $0,76 \mathrm{ab}$ \\
\hline 15 & $0,85 \mathrm{a}$ & $0,88 \mathrm{ab}$ & $0,82 \mathrm{ab}$ \\
\hline \multirow[t]{2}{*}{22} & $0,82 \mathrm{a}$ & $0,82 \mathrm{ab}$ & $0,74 \mathrm{ab}$ \\
\hline & \multicolumn{3}{|c|}{ Sólidos solúveis totais $\left({ }^{\circ} \mathrm{Brix}\right)$} \\
\hline 0 & $8,12 \mathrm{a}$ & $9,32 \mathrm{a}$ & $8,50 \mathrm{a}$ \\
\hline 8 & $9,50 \mathrm{a}$ & $9,42 \mathrm{a}$ & $10,50 \mathrm{a}$ \\
\hline 15 & $12,12 \mathrm{a}$ & $11,83 \mathrm{a}$ & $12,17 \mathrm{a}$ \\
\hline \multirow[t]{2}{*}{22} & $11,67 \mathrm{a}$ & $11,75 \mathrm{a}$ & $12,00 \mathrm{a}$ \\
\hline & \multicolumn{3}{|c|}{ Relação SST/ATT } \\
\hline 0 & $8,92 \mathrm{a}$ & $9,81 \mathrm{a}$ & $8,95 \mathrm{a}$ \\
\hline 8 & $12,18 \mathrm{a}$ & $11,35 \mathrm{a}$ & $13,82 \mathrm{a}$ \\
\hline 15 & $14,26 \mathrm{a}$ & $13,44 \mathrm{a}$ & $14,84 \mathrm{a}$ \\
\hline 22 & $14,23 \mathrm{a}$ & $14,33 \mathrm{a}$ & $16,22 \mathrm{a}$ \\
\hline
\end{tabular}

${ }^{1}$ Valores seguidos pelas mesmas letras na horizontal não diferem entre si pelo teste de Tukey, a $5 \%$ de probabilidade. ferença significativa entre os tratamentos $(2 \%$ e $4 \%)$ e o controle $(0 \%)$. O teor de sólidos solúveis totais apresentou pequena variação entre os tratamentos, aumentou de forma acentuada até o $15^{\circ}$ dia de armazenamento, e, a partir daí, os valores mantiveram-se relativamente constantes. Quanto ao $\mathrm{pH}$, à acidez, e aos sólidos solúveis, os dados obtidos aproximados mostram pequenas variações ao longo do armazenamento, bem como entre os tratamentos. A relação sólidos solúveis/acidez inicial (entre 9 e 10) foi semelhante entre os tratamentos, e houve elevação durante o período de armazenamento, atingindo valores entre 13 e 16 . O tratamento com $4 \%$ de $\mathrm{CaCl}_{2}$ apresentou acidez menor, teor de sólidos solúveis maior, e, conseqüentemente, maior relação sólidos solúveis/acidez durante todo o período de armazenamento, em comparação com os outros dois tratamentos. Em relação ao $\mathrm{pH}$, aos sólidos solúveis e à relação sólidos solúveis/acidez, pela análise de regressão das médias observadas, não houve diferenças significativas quanto aos níveis de $\mathrm{Ca}$ adicionado.

O comportamento das características de $\mathrm{pH}$, dos sólidos solúveis, da relação sólidos solúveis/acidez (aumento) e da acidez total (decréscimo), apresentou tendência normal, diante do avanço da maturação dos frutos, e não havendo efeito aparente do Ca nessas avaliações.

Após o $4^{\circ}$ dia, à temperatura ambiente, quando os frutos completaram o amadurecimento, as médias dos valores atribuídos aos frutos, quanto às características observadas, são apresentadas na Tabela 6. A aparência externa dos frutos mostra que o controle $\left(0 \%\right.$ de $\left.\mathrm{CaCl}_{2}\right)$ apresentou sintomas severos de antracnose, ao contrário dos tratamentos com $2 \%$ (sintomas moderados) e $4 \%$ de $\mathrm{CaCl}_{2}$ (Fig. 2). Os frutos tratados com $4 \% \mathrm{de} \mathrm{CaCl}_{2}$, apresentaram melhor aparência geral, porém com lesões leves, o que poderia comprometer a exportação. Os frutos não apresentaram colapso interno em nenhum dos tratamentos. Quanto aos resultados obtidos em relação ao Ca total na casca dos frutos, observam-se valores maiores no tratamento com $4 \%$ de $\mathrm{CaCl}_{2}$, porém não significou aumento do teor de Ca na polpa, da qualidade dos frutos, nem do período de armazenamento. Quanto ao Ca na polpa, observamse quantidades semelhantes, o que indica que a pe- 
TABELA 6. Valores médios das características da manga cv. Tommy Atkins submetida a imersão pós-colheita a 46,1 ${ }^{\circ} \mathrm{C}$, por 90 minutos, em $\mathrm{CaCl}_{2}$, tratada com diferentes níveis de $\mathrm{Ca}$, armazenada por 22 dias a $10^{\circ} \mathrm{C} \pm 1^{\circ} \mathrm{C}$ e $85 \% \pm 5 \%$ de umidade relativa e por mais quatro dias sob condições ambientes.

\begin{tabular}{lccc}
\hline Característica & \multicolumn{3}{c}{ Tratamento $\left(\mathrm{CaCl}_{2}\right)$} \\
\cline { 2 - 4 } & $0 \%$ & $2 \%$ & $4 \%$ \\
\hline Textura (newton) & $33,81 \pm 3,56$ & $28,56 \pm 1,78$ & $32,07 \pm 3,11$ \\
Aparência interna (nota atribuída) & $1,0 \pm 0,0$ & $1,0 \pm 0,0$ & $1,0 \pm 0,0$ \\
Aparência externa (nota atribuída) & $3,5 \pm 0,5$ & $2,5 \pm 0,5$ & $2,0 \pm 0,0$ \\
pH & $3,71 \pm 0,01$ & $3,89 \pm 0,00$ & $3,88 \pm 0,00$ \\
Sólidos solúveis totais ( ${ }^{\circ}$ Brix) & $11,75 \pm 0,25$ & $11,25 \pm 0,25$ & $12,00 \pm 0,0$ \\
Acidez (\% ác. cítrico) & $0,76 \pm 0,01$ & $0,82 \pm 0,01$ & $0,72 \pm 0,01$ \\
Ratio (relação SST/ATT) & 15,46 & 13,72 & 16,67 \\
Pectina total (mg ác.galact./100 g) & $786,22 \pm 20$ & $744,35 \pm 20$ & $744,84 \pm 20$ \\
Cálcio na casca (\%) & $0,299 \pm 0,003$ & $0,281 \pm 0,002$ & $0,335 \pm 0,002$ \\
Cálcio na polpa (\%) & $0,093 \pm 0,001$ & $0,092 \pm 0,003$ & $0,095 \pm 0,003$ \\
\hline
\end{tabular}

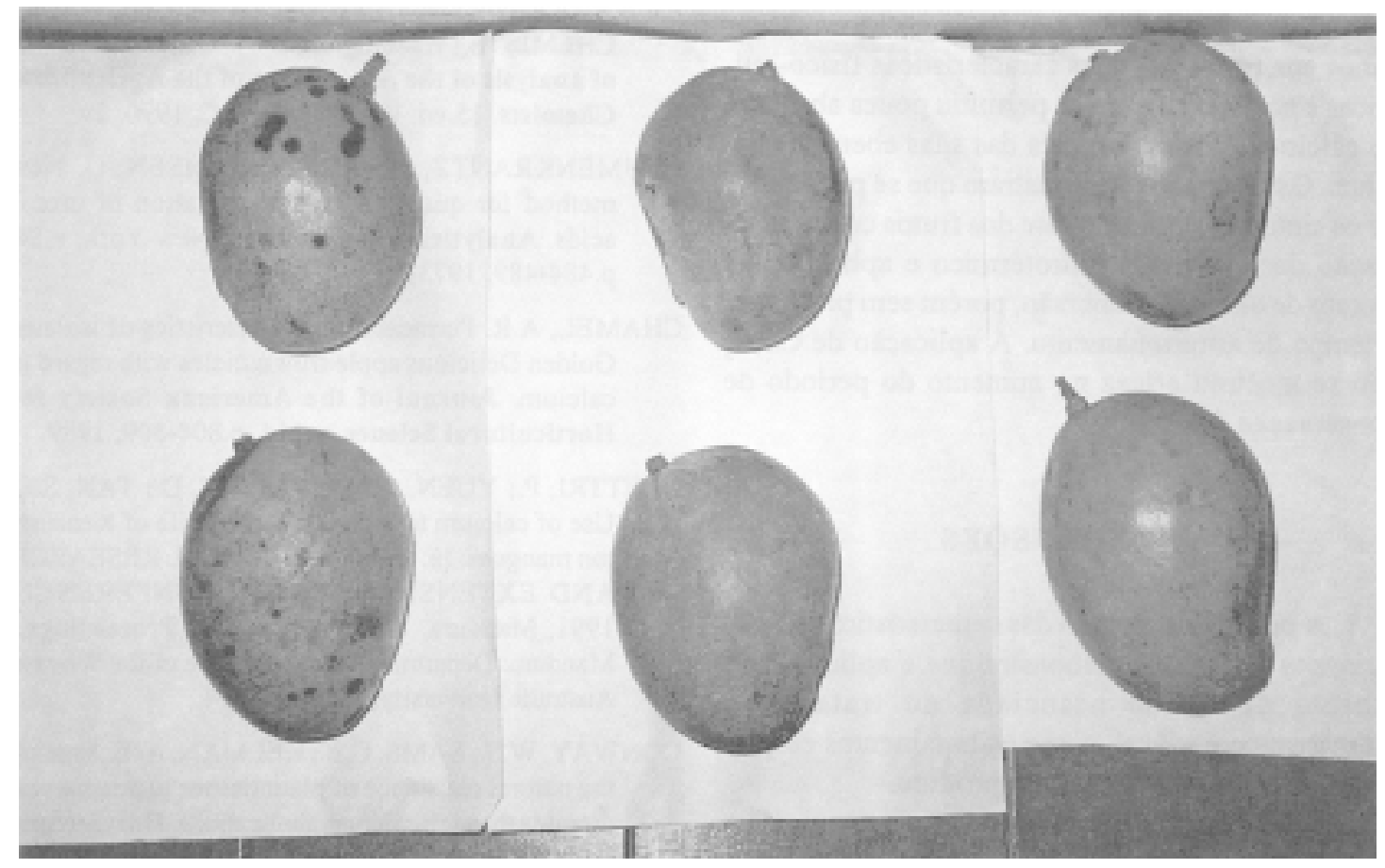

FIG. 2. Aparência externa final dos frutos da mangueira cv. Tommy Atkins submetida a imersão pós-colheita a $46,1^{\circ} \mathrm{C}$, por 90 minutos, em $0 \%, 2,0 \%$ e $4,0 \%$ de $\mathrm{CaCl}_{2}$, armazenada por 22 dias, a $10^{\circ} \mathrm{C} \pm 1^{\circ} \mathrm{C}$ e $\mathbf{8 5 \%} \pm \mathbf{5 \%}$ de umidade relativa, e mais quatro dias à temperatura ambiente (mesmo fruto de cada tratamento, em duas posições). 
netração do Ca pela casca é difícil, em face da sua pouca mobilidade, fato confirmado por Chamel (1989).

Os frutos apresentaram queda acentuada na resistência à penetração, como era esperado, semelhante em todos os tratamentos, variando entre 28,56 a 33,81 newtons. Os valores encontrados relativamente à pectina total mostram poucas variações entre os tratamentos. Desta forma, não houve efeito da aplicação do Ca na manutenção da firmeza dos frutos. Quanto ao $\mathrm{pH}$, à acidez e aos sólidos solúveis, os valores encontrados mostram poucas diferenças entre os tratamentos, o que demonstra que os tratamentos com Ca não apresentaram efeitos aparentes. No final do experimento, os frutos se apresentavam maduros e próprios para o consumo.

$\mathrm{O}$ tratamento hidrotérmico associado com $\mathrm{CaCl}_{2}$, aplicado neste experimento, não demonstrou causar danos aos frutos nas suas características físico-químicas e no aspecto geral, e permitiu pouca absorção do cálcio pelo fruto, através das suas aberturas naturais. Os resultados demonstram que se pode reduzir os sintomas de antracnose dos frutos com a associação do tratamento hidrotérmico e aplicação de cloreto de cálcio por imersão, porém sem prolongar o tempo de armazenamento. A aplicação de $\mathrm{CaCl}_{2}$ não se mostrou eficaz no aumento do período de conservação dos frutos.

\section{CONCLUSÕES}

1. A pequena alteração das características físicoquímicas dos frutos demonstra que a aplicação de cloreto de cálcio associada ao tratamento hidrotérmico é viável, e que os tratamentos empregados não são prejudiciais ao produto.

2. Existe uma correlação positiva entre o cálcio aplicado e a quantidade deste elemento na casca, mas com pouca penetração para a polpa do frutos.

3. O cálcio age positivamente na diminuição dos sintomas da antracnose.

4. A aplicação de cloreto de cálcio a $4 \%$ mostra melhores resultados, mas não garante a qualidade final do produto e nem aumenta seu tempo de armazenamento.

\section{AGRADECIMENTOS}

À Frunorte (Dr. Manoel Dantas) e ao Prof. Josivan B. Menezes (ESAM - Mossoró), pela doação, apoio na seleção e remessa dos frutos; à Profa. Maria Isabel F. Chitarra, pelas sugestões apresentadas na discussão dos resultados; e à Elisabeth B. Gonçalves (Embrapa-CTAA), pelo apoio nas análises estatísticas.

\section{REFERÊNCIAS}

AINA, J.O.; OLADUNJOYE, O.O. Respiration, pectolytic activity and textural changes in ripening African mango (Irvingia gabonensis) fruits. Journal of the Science of Food and Agriculture, v.63, p.451-454, 1993.

ASSOCIATION OF OFFICIAL AGRICULTURAL CHEMISTS (Washington, DC). Official methods of analysis of the Association of the Agricultural Chemists. 15.ed. Washington, DC, 1990. 2v.

BLUMENKRANTZ, N.; ASBOE-HANSEN, G. New method for quantitative determination of uronic acids. Analytical Biochemistry, New York, v.54, p.484-489, 1973.

CHAMEL, A.R. Permeability characteristics of isolated Golden Delicious apple fruit cuticles with regard to calcium. Journal of the American Society for Horticultural Science, v.114, p.804-809, 1989.

CHETTRI, P.; YUEN, C.M.C.; JOYCE, D.; TAN, S.C. Use of calcium to increase storage life of Kensington mangoes. In: HORTICULTURAL RESEARCH AND EXTENSION UPDATE CONFERENCE, 1991, Mandura, Western Australia. Proceedings... Mandura: Department of Agriculture of the Western Australia University, 1991. p.11-14

CONWAY, W.S.; SAMS, C.E.; KELMAN, A. Enhancing the natural resistance of plant tissues to postharvest diseases through calcium applications. HortScience, v.29, p.751-754, 1994.

CUNHA, M.M. da; COUTINHO, C. de C.; JUNQUEIRA, N.T.V.; FERREIRA, F.R. Manga para exportação: aspectos fitossanitários. Brasília: MAARA-SDR/Embrapa-SPI, 1993. 104p. (Série publicações técnicas Frupex, 3).

FILGUEIRAS, O. Mercado com sabor de muitos dólares. Globo Rural, v.6, n.60, p.14-15, 1990. 
GORGATTI NETTO, A.; GAYET, J.P.; BLEINROTH, E.W.; MATALLO, M.; GARCIA, A.E.; ARDITO, E.F.G.; GARCIA, E.E.C.; BORDIN, M.R. Manga para exportação: procedimentos de colheita e póscolheita. Brasília: MAARA-SDR/Embrapa-SPI, 1993. 44p. (Série publicações técnicas Frupex, 4).

INSTITUTO ADOLFO LUTZ. Normas analíticas do Instituto Adolfo Lutz. 2.ed. São Paulo, 1976. v.1, $175 p$.

INSTITUTO BRASILEIRO DE FRUTAS (São Paulo, $\mathrm{SP})$. Evolução das exportações brasileiras de frutas frescas: uma análise crítica. São Paulo: IBRAF/DATAFRUTA, 1993. 41p.

MARSCHENER, H. Mineral nutrition of higher plants London: Academic Press, 1986. 876p

McCOLLUM, T.G.; HUBER, D.J.; CANTLIFFE, D.J Modification of polyuronides and hemicelluloses during muskmelon fruit softening. Physiologia Plantarum, Copenhagen, v.76, p.303-308, 1989
McCREADY, P.M.; McCOMB, E.A. Extraction and determination of total pectin material. Analytical Chemistry, Washington, DC. v.24, n.12, p.1586$1588,1952$.

MICCOLIS, V.; SALTVEIT, M.E. Influence of storage period and temperature on the postharvest characteristics of six melon (Cucumis melo L., Inodorus Group) cultivars. Postharvest Biology and Technology, v.5, p.211-219, 1995.

POOVAIAH, B.W. Molecular and cellular aspects of calcium action in plants. HortScience, v.23, p.267271,1988

SARRUGE, J.R.; HAAG, H.P. Análises químicas em plantas. Piracicaba: ESALQ, 1974. 56p.

YUEN, C.M.C.; TAN, S.C.; JOYCE, D.; CHETTRI, P. Effect of postharvest calcium and polimeric films on ripening and peel injury in Kensington Pride mango. ASEAN Food Journal, v.8, n.3, p.110-113, 1993. 